Revue bibliographique pour le domaine irano-aryen

\title{
Nestor Kavvadas. Isaak von Ninive und seine Kephalaia Gnostika. Die Pneumatologie und ihr Kontext
}

Florence Jullien

\section{OpenEdition}

1 Journals

\section{Édition électronique}

URL : http://journals.openedition.org/abstractairanica/45250

DOI : 10.4000/abstractairanica.45250

ISBN : 1961-960X

ISSN : 1961-960X

Éditeur :

CNRS (UMR 7528 Mondes iraniens et indiens), Éditions de l'IFRI

Référence électronique

Florence Jullien, « Nestor Kavvadas. Isaak von Ninive und seine Kephalaia Gnostika. Die Pneumatologie und ihr Kontext », Abstracta Iranica [En ligne], Volume 37-38-39 | 2018, document 42, mis en ligne le 30 décembre 2018, consulté le 02 octobre 2020. URL : http://journals.openedition.org/abstractairanica/ 45250 ; DOI : https://doi.org/10.4000/abstractairanica.45250

Ce document a été généré automatiquement le 2 octobre 2020.

Tous droits réservés 


\title{
Nestor Kavvadas. Isaak von Ninive und seine Kephalaia Gnostika. Die Pneumatologie und ihr Kontext
}

\author{
Florence Jullien
}

\section{RÉFÉRENCE}

Nestor Kavvadas. Isaak von Ninive und seine Kephalaia Gnostika. Die Pneumatologie und ihr Kontext. Leiden: Brill, 2015, 193 p. ISBN 9789004284838, (Vigiliae Christianae, Supplements. Texts and Studies of Early Christian Life and Language 128)

1 Après les importantes publications de S. P. Brock (1995) et de S. Chialà $(2011 ; 2013)$ qui ont livré les éditions critiques et les traductions des $I I^{e}$ et $I I I^{e}$ parties, et quelques fragments de la $V^{e}$, le corpus des œuvres d'Isaac de Ninive est désormais mieux connu. L'A. livre ici une mise en contexte de la pensée d'Isaac dans le cadre du développement de la tradition mystique au sein de l'Église syro-orientale. Par ailleurs, il offre une édition des chapitres gnostiques jusque-là inédits à partir du manuscrit conservé à la Bodleian Library. Il s'agit d'une version révisée de sa thèse de théologie soutenue en 2011 à Tübingen. L'ouvrage est organisé en deux sections. La première, subdivisée en quatre chapitres, donne le contexte du différend qui opposa la hiérarchie officielle de l'Église de l'Est et les mystiques syro-orientaux eux-mêmes sur la question des mystiques et des pratiques mystiques. L'A. est d'avis que le terme "messalien » utilisé dans les synodes, spécialement sous Timothée ${ }^{\mathrm{er}}$, aurait aussi désigné les mystiques et les moines dont il définit l'identité, dès le $\mathrm{VI}^{\mathrm{e}}$ siècle, par un fort anachorétisme et une remise en question de la nature de l'autorité spirituelle au sein de l'Église (autorités hiérarchiques, canons et ordonnances liturgiques, rites, médiatisation de la connaissance par les centres d'enseignement scholastique et le magistère ecclésial, etc.). La seconde partie présente en cinq sections une analyse synthétique de la pneumatologie d'Isaac dans ses chapitres gnostiques. L'A. met en lumière un modèle 
mystique de l'autorité spirituelle, qui trouve ses racines dans la culture et l'héritage spirituel syro-orientaux.

\section{AUTEURS}

\section{FLORENCE JULLIEN}

CNRS, Mondes iranien et indien, Paris 